\title{
Fine Single Sand Body Characterization of Hulangmao Chang 6 Reservoir in Jing'an Oilfield
}

\author{
Yan Yunbiao ${ }^{1}$, Zhang Jinxin ${ }^{1}$, Pang Yuxin ${ }^{1}$, Li Cunlei ${ }^{1, ~}{ }^{\text {, }}$, Yu Bo ${ }^{2}$, Zhou Yigang ${ }^{1}$, Tang Shiqi ${ }^{1}$ \\ ${ }^{1}$ College of Petroleum Engineering, Liaoning Shihua University, Fushun, China \\ ${ }^{2}$ Baikouquan Oil Production Plant of Petrochina Xinjiang Oilfield Branch, Kelamayi, China
}

\section{Email address:}

cunleilee@126.com (Li Cunlei)

${ }^{*}$ Corresponding author

\section{To cite this article:}

Yan Yunbiao, Zhang Jinxin, Pang Yuxin, Li Cunlei, Yu Bo, Zhou Yigang, Tang Shiqi. Fine Single Sand Body Characterization of Hulangmao Chang 6 Reservoir in Jing'an Oilfield. Journal of Energy and Natural Resources. Vol. 9, No. 4, 2020, pp. 111-119.

doi: $10.11648 /$ j.jenr.20200904.12

Received: November 16, 2020; Accepted: December 4, 2020; Published: December 11, 2020

\begin{abstract}
The Chang 6 reservoir in Hulangmao area is a lithologic reservoir controlled by Zhidan Jingbian delta depositional system in Northern Shanxi Province. The oil reservoir has entered the middle-high-water-cut stage. The reservoir is characterized by low porosity and low permeability, with strong heterogeneity and great development difficulty. Therefore, it is necessary to further study the distribution of remaining oil through fine single sand body division and correlation, so as to improve the level of the reservoir development. Based on the theory of high-resolution sequence stratigraphy, according to the characteristics of mudstone marker bed and logging combinations, the sedimentary cycles are studied by using the techniques of maximum entropy spectrum and wavelet transform, and the cycle characteristics of different levels are clarified. Chang 6 member is divided into 3 fourth-level cycles, 6 fifth-level cycles (small levels), 13 sixth-order cycles (single level), and 21 seventh-order cycles (single sand body). Based on the stratigraphic correlation analysis model of sand body equal thickness, channel down-cutting, lateral phase transformation and splitting of superimposed sand body, and combined with the core and logging characteristics of the target area, the correlation framework of single sand layer in the whole area is established.
\end{abstract}

Keyword: Hulangmao Chang 6 Reservoir, Cyclical Correlation, Fine Single Sand Body, Stratigraphic Correlation Framework

\section{Introduction}

The Chang 6 reservoir in Hulangmao area is characterized by poor physical properties and strong heterogeneity, and the development of multi-layer system has resulted in prominent inter layer contradictions. Since the large-scale development in 2002, the development technology policy with separate layer water injection as the core has been continuously optimized, and the control and treatment of cross-section and low-yield wells have also been continuously carried out $[1,2]$. However, due to the complicated relationship between injection and production, uneven profile water absorption and relatively high productivity, it is difficult to produce remaining oil. And it is urgent to make a detailed and systematic distinction and comparison of single layer in Hulanglao Chang 6 reservoir
The theoretical basis used in this paper is mainly supported by sedimentology and high-resolution sequence stratigraphy. With the help of maximum entropy spectrum analysis and wavelet analysis, the paper adopts the technical means of "dividing layers by analysis attributes, determining interface between core and logging, and dividing correlation into small layers", so as to realize the identification, differentiation and comparison of base-level cycle sequences in the study area. At the same time, the sequence stratigraphy corresponding to a single wells is compared and distinguished, and the results are finally analyzed and researched. Based on the identification of logging facies, the fine division of single sand body is carried out in the target horizon of Chang $6_{1}{ }^{2}$ to Chang $6_{2}^{2}$. Finally, a high-resolution sequence stratigraphic comparison framework 
of single sand layer in Chang 6 member of Hulanglao is created.

\section{Geological Setting}

The Ordos Basin belongs to secondary structural unit of North China Craton, which is located in the central and western part of the North China. As a world-class energy basin with huge oil and gas reserves, the basin structure has significant depression transfer and torsion. The thickness of its internal sedimentary rocks is about $5000-10000 \mathrm{~m}$, and the subsidence is usually stable. The underling strata are derived from Archean and Proterozoic metamorphic batholiths. From the perspective of the structural characteristics of the basin, the western part of the basin is declining, while the eastern part is rising, and the terrain is higher in the east and lower in the west. On the whole, it is relatively gentle, and the gradient value per kilometer is less than $1^{\circ}[3,4]$ (Figure 1, A).

The Hulanglao district is located in Zhidan County, Shan'xi Province. The internal structure of this area is mainly west inclined monocline. The slope value corresponding to each kilometer in the stratum is generally within 7-10 $\mathrm{m}$. And there is a low-amplitude nose-like bulge locally (Figure 1, B). The Quaternary in the area directly unconformably covers the Triassic Yanchang Formation. Drilling data reveals the middle and upper strata of the Triassic Yanchang Formation. Among them, the change of residual thickness of Chang 6 oil-bearing group of Yanchang Formation is relatively stable, and it is the main oil-producing layer, which belong to typical low-permeability reservoir [5, 6] (Figure 1, C).

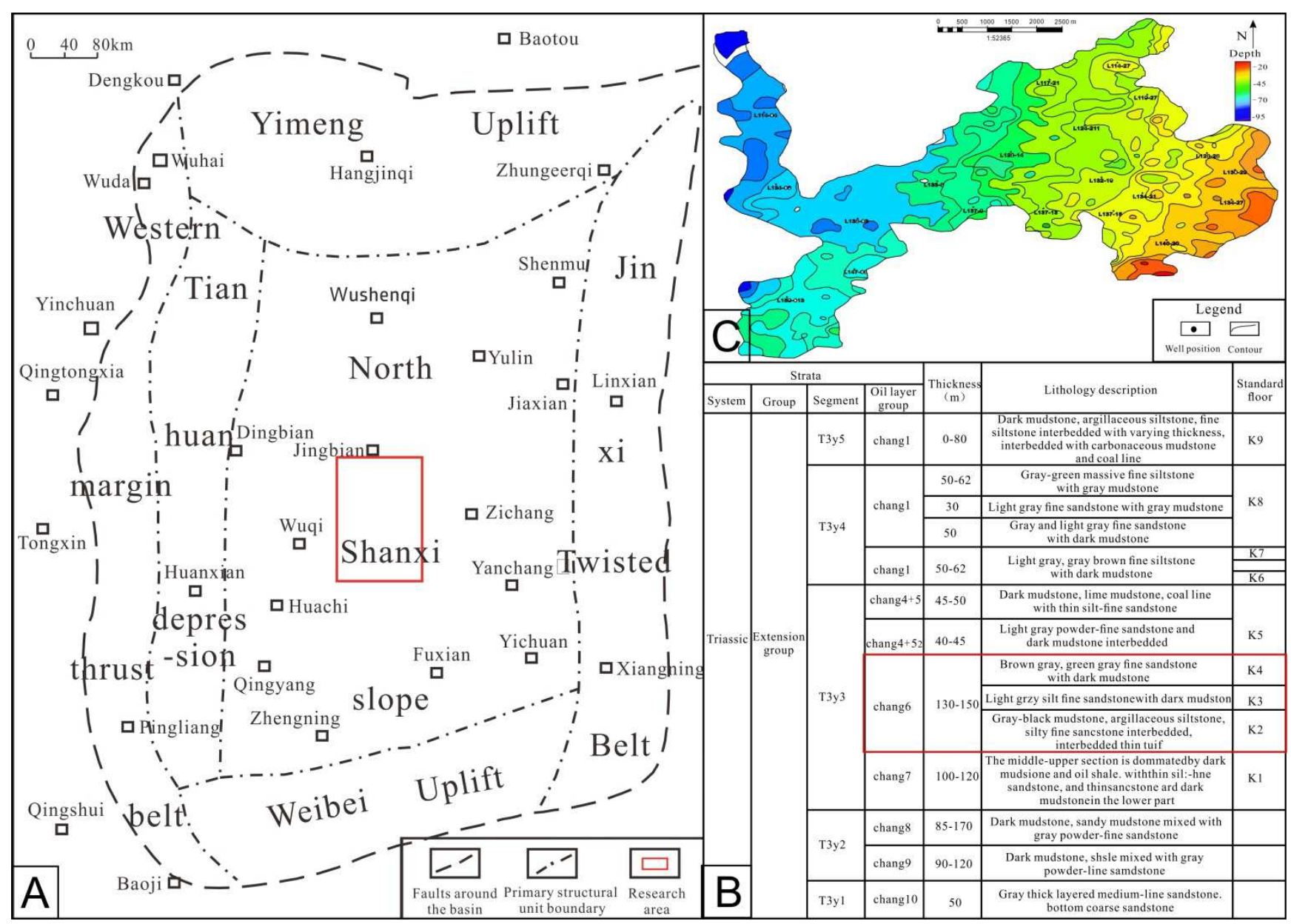

Figure 1. The structural map of Hulangmao Chang 6 reservoir.

\section{Analysis of Stratigraphic Cycle Features}

Based on the research premise of the cyclic characteristics of lithological changes on the surface of the formation, this paper uses lithology and logging characteristics as the basis, and uses maximum entropy spectrum analysis and wavelet analysis to complete the comparison and differentiation of related cycles.

\subsection{Wavelet Analysis Method}

The wavelet transform uses logging data for analysis. The shape is stable and the characterization is significant. It can well reflect the subsidence behavior and evolution law of the measured section. Logging curves such as AC, GR and SP can reflect information such as cuttings, grain size change, mud quality, etc. to a certain extent. After comparative analysis of wavelet transform, it is obvious that the wavelet coefficient map of the natural gamma curve is optimal select (Figure 2). 

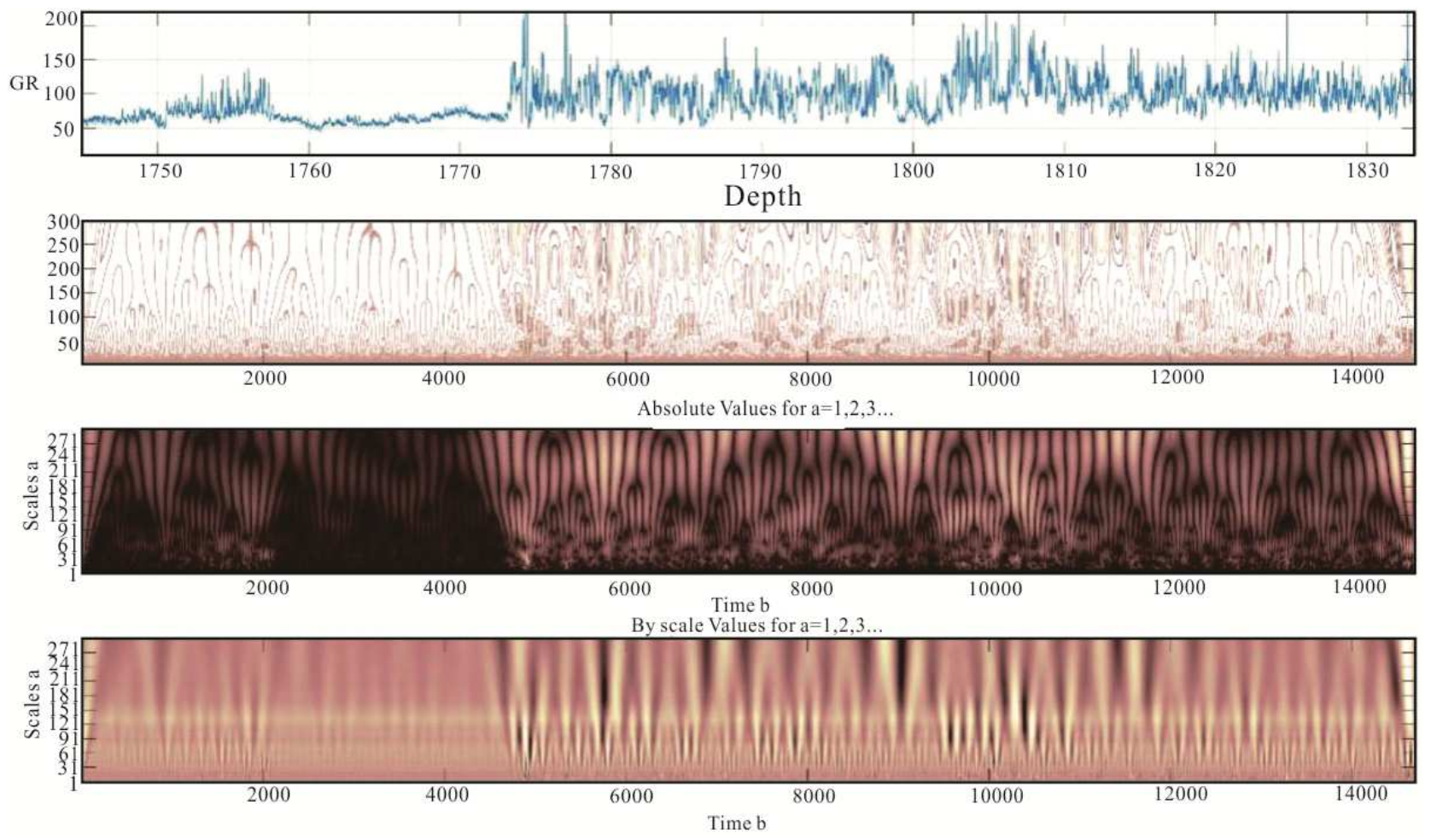

Figure 2. Wavelet scale chromatogram of $A C, G R, S P$ logging data.

The main software used in this thesis for wavelet analysis of logging data is MATLAB. The depth indicated by the wavelet spectrogram and coefficient curve can well correspond to all levels of sequence interface, and easy to identify. In the time-frequency chromatogram, the lighter part of the time-frequency chromatogram represents the wavelet system with larger modulus and higher energy, and the darker part with smaller wavelet coefficient modulus and lower energy; the gradual change of color from light to dark means that the modulus value increases from large to small. Represents a retrograde sequence cycle. During this period, the deposition rate gradually decreases and the sand-soil ratio decreases, indicating the sedimentary characteristics of transgression or water ingress. On the contrary, it represents a progressive sequence cycle. The increase in ratio indicates the sedimentary characteristics of regression or regression $\mathrm{s}$ $[7,8]$.

After the transformation, the frequency of the logging curve can be clearly seen. The larger the longitudinal span of the curve, the smaller the displayed signal frequency and the weaker the ability to divide the sequence. At this time, it shows a long period and a large thickness. For sedimentary characteristics, if the longitudinal span of the curve is more opposite, the result obtained is the opposite [9, 10]. Taking well Liu122-271 as an example, according to the above analysis, it has been divided and divided into sequence units of different levels. Among them, there are 14 ultra-short-term cycles corresponding to a single sand layer (Figure 3).

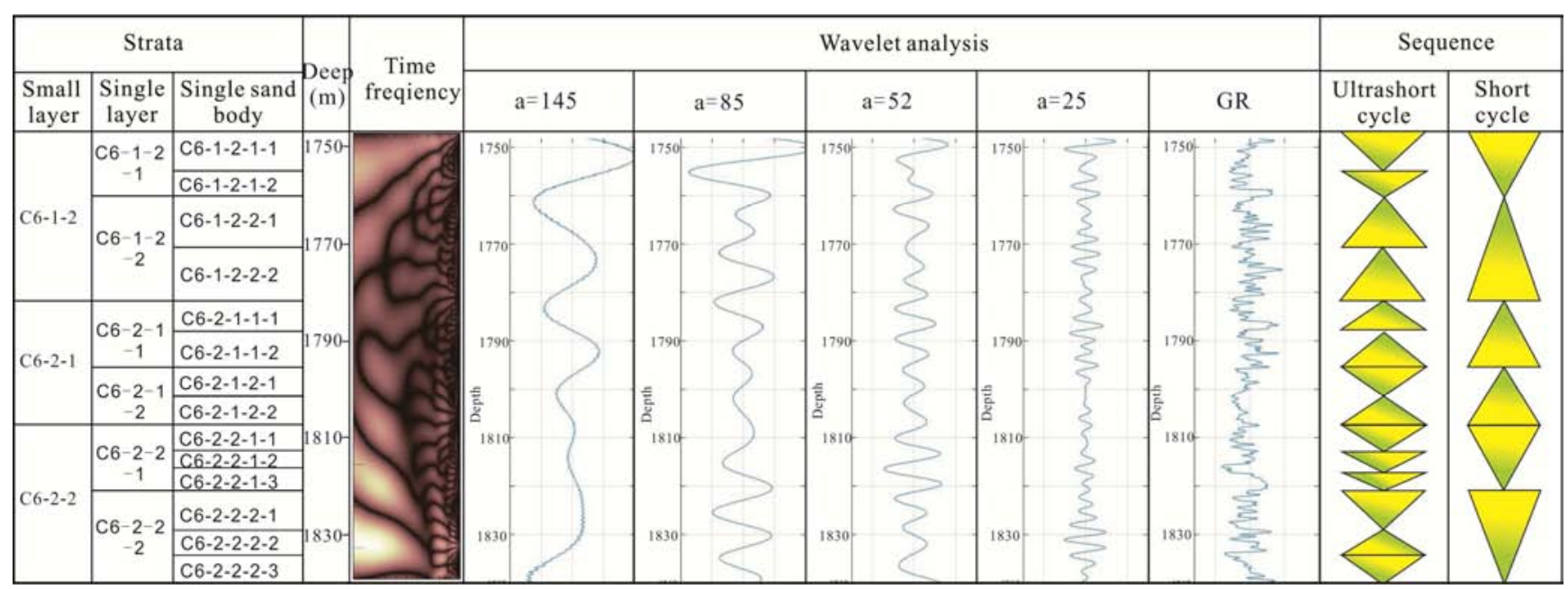

Figure 3. Schematic diagram of the theory of wavelet analysis identifying sedimentary cycles. 


\subsection{Maximum Entropy Spectrum Analysis Method}

The so-called maximum entropy spectrum analysis mainly refers to the method of extrapolation operation and obtaining the relevant autocorrelation function according to the principle of maximum entropy. Based on the premise of maximum entropy, prediction calculation and analysis error filtering analysis are performed. On the basis of knowing the specific value of the known point, the next value is calculated based on the maximum entropy, and the obtained value is the estimated value. The difference between the specific value and the estimated value of maximum entropy spectrum analysis is the prediction error, from which we can obtain a theoretical reference for the receding lake: when the value is positive, then it means that the predicted value is smaller than the actual measured value. The conclusion drawn from this is that the sediment content of mud is increasing, so the water body tends to deepen, resulting in the water ingress process. When the value is less than zero, the actual measured value is less than the predicted value, which is manifested as a decrease in the content of muddy sediments and an increase in the content of sand bodies, thus the trend of the water body becomes shallow
$[11,12]$. The cumulative effect of the lake retreat over time can be obtained by integrating the error data. Therefore, after the integration processing, the synthetic prediction error filtering analysis curve INPEFA can be obtained. The positive trend in the INPEFA curve indicates that the A/S value increases. From left to right, the curve value increases and the shape increases. That is, the stratum rises in a semi-cycle, and the environment in the process of stratum deposition gradually becomes humid; the negative trend is the opposite, which corresponds to a descending semi-cycle, indicating a gradual arid regressive process $[13,14]$.

As shown in Figure 4, taking well Liu122-271, Liu123-27, Liu125-25, and Liu126-24 as examples, the application of synthetic prediction error filtering analysis in this sequence stratigraphic division is shown. The corresponding cyclic characteristics corresponding to the strata can be shown by the spectral attribute trend curve. In addition, with the help of the comparative analysis between multiple wells, combined with logging and core data at the same time, completed the analysis of the base level cycle and divided the well into fourteen different single sand cycle units.

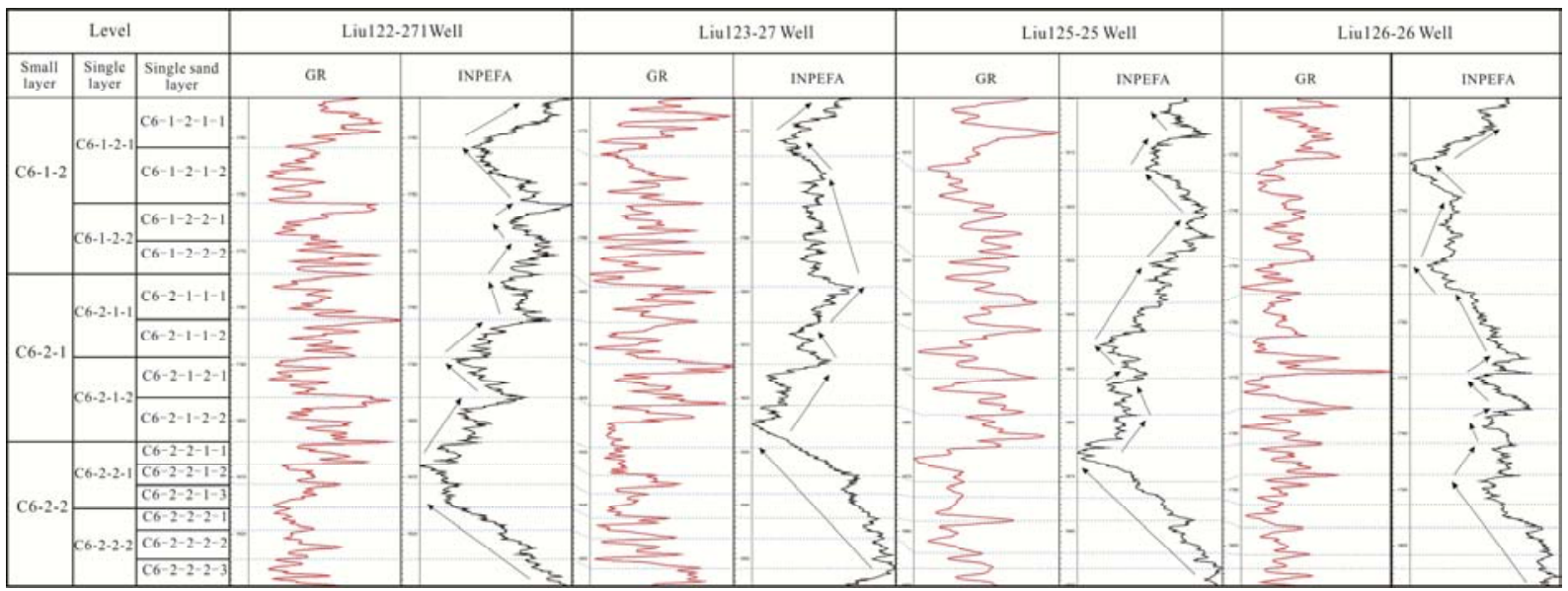

Figure 4. Maximum entropy spectrum analysis of logging curve.

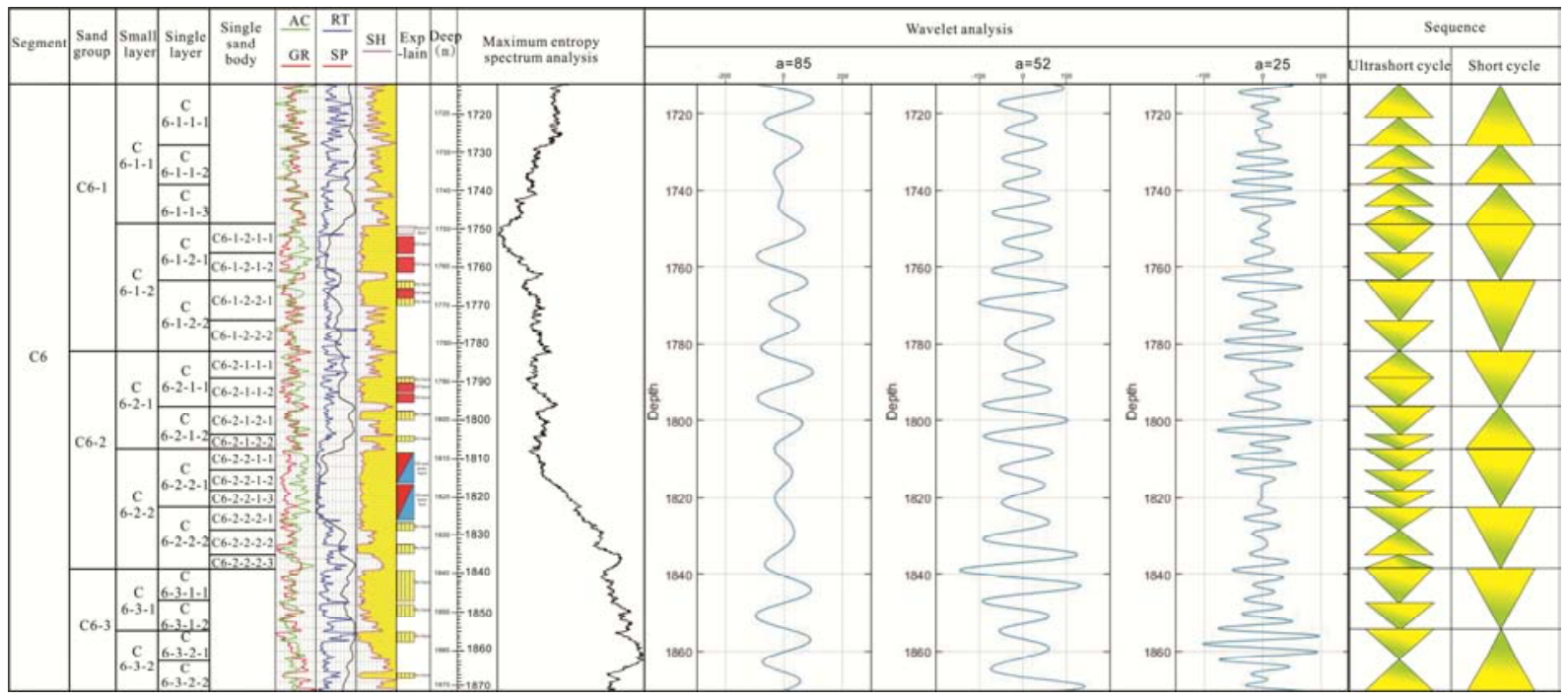

Figure 5. Cycle division plan of Well Liu122-271. 


\subsection{Cycle Division Scheme}

Compared with the traditional division of cycles, this division is based on the theory of wavelet analysis and maximum entropy spectrum analysis of sedimentary cycles. On the basis of studying the distribution characteristics of well marker bed and sedimentary cycle change rules, combined with the characteristics of marker bed and logging combination, the single well cycle scheme is divided on the basis of determining the number of single sand body from large to small, from coarse to fine [15]. For example, the Chang $6_{1}$ and Chang $6_{2}$ sand formations in well Liu122-271 are compound rhythms composed of multiple sedimentary small cycles. Chang $6_{1}$ and Chang $\sigma_{2}$ are box-shaped sedimentary small cycles. With this data, the following sand formation division can be carried out. As shown in Figure 5 . the cycle division scheme of wells in the study area is shown.

\section{Single Sand Layer Comparison Method}

\subsection{Recognition of Single Sand Body Finely Depicted Marking Layer}

The distribution law of the marker layer and the cyclic changes of sedimentation are the basis for the comparison of single sand layers. The typical standard layer has the top of
Chang 6 oil-bearing formation: high-resistance or box-shaped retrocyclic deposition; the bottom of Chang 6 oil-bearing formation: the high-resistance peak-shaped mark layer of each layer. These marker bed are easy to identify on cores and logging profiles, are distributed stably, and have excellent isochronism across the entire region. Through statistics, it is found that there are four local marker beds in Hulangmao Chang 6 reservoir, The marker bed are distributed stably in the area, with obvious rock and electrical characteristics, easy to trace and compare, and can be used as the basis for stratigraphic division and comparison in this area [16-18].

(1) Marker bed (K3): The bottom of Chang $6_{3}{ }^{1-2}$, the lithology is the interbedding of gray-black mudstone, argillaceous siltstone and fine sandstone, which is characterized by low resistance, low density, and high GR (Figure 6a).

(2) Marker bed (K4): The bottom of Chang $6_{2}{ }^{1-2}$, mainly represented by gray mudstone, argillaceous fine siltstone, high AC, high GR, and low resistance (Figure $6 b)$.

(3) Marker bed: The bottom of Chang $6_{1}{ }^{2-1}$, mainly manifested as box-shaped sandstone, and the GR curve presents a box-shaped or positive rhythm with a sudden change at the bottom (Figure 6c).

(4) Marker bed: Chang $6_{1}^{1-1}$, mainly represented by dark mudstone, high AC, high SP, and low resistance, sharp knife-shaped well diameter (Figure 6d).

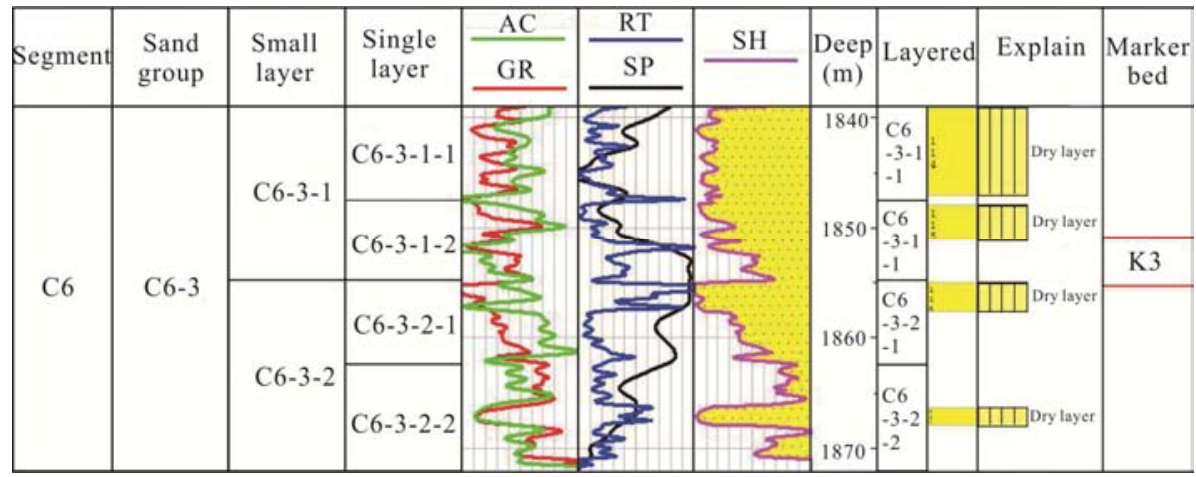

(a). The Marker bed of K3

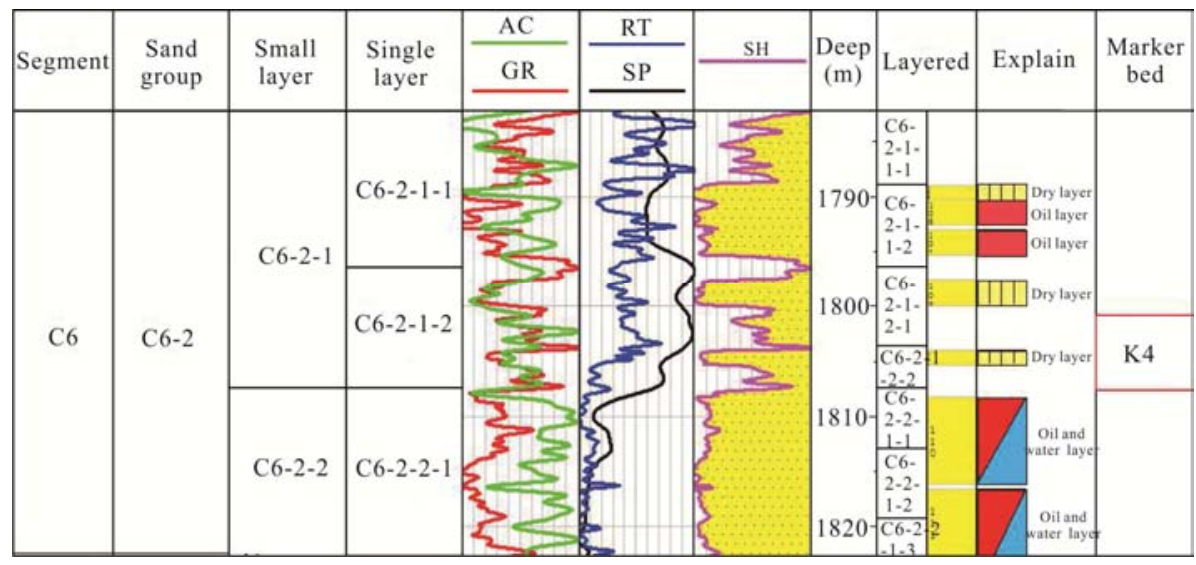

(b). The Marker bed of K4 


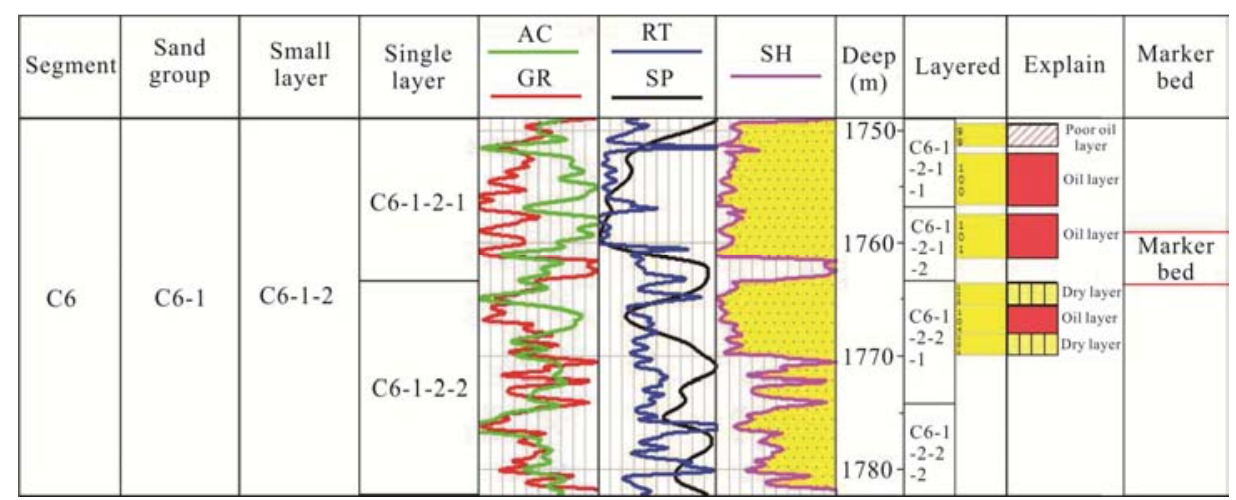

(c). The Marker bed of the bottom of Chang $6_{1}^{2-1}$

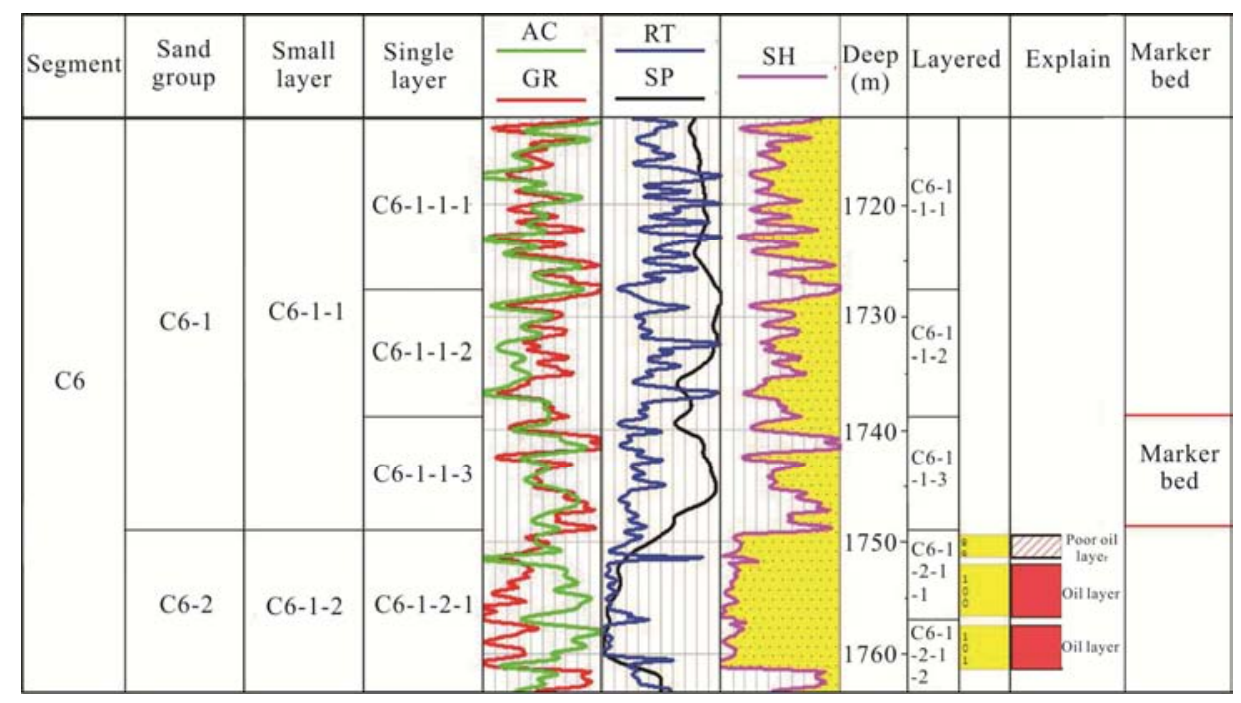

(d). The Marker bed of Chang $6_{1}{ }^{1-1}$

Figure 6. Sign layer distribution feature map.

\subsection{Classification and Comparison of Single Sand Layer}

According to the collected data, the layers divided by the Chang 6 oil-bearing formation in the study area are very fine and the sand bodies are unstable, so it is difficult to identify a unified marker layer on the $\log$ [19]. Refer to the predecessor's small-layer division scheme, select high-resolution sequence stratigraphy theory, combined with maximum entropy spectrum analysis, wavelet analysis as the basic research method. According to logging characteristics, the original six single layers are divided into fourteen single sands by means of equal thickness, channel undercutting, lateral phase change, and splitting of overlapping sand bodies.

In addition, in the subdivision of the single sand layer, according to the characteristics of lithological changes, the interlayer (muddy interlayer, calcicolous interlayer and physical property interlayer) and the obvious lithofacies difference are regarded as the local signs of the single sand layer division. The division and comparison of single sand bodies is carried out under an accurate isochronous framework to ensure the accuracy of the formation period of single sand bodies.

\subsubsection{Principles for Dividing Single Sand Layer}

The principle of division and correlation of single sand layer of wells in the study area is as follows.

(1) In a single sand layer with the same lithology, its electrical combination characteristics have the same characteristics. It should be noted that under special circumstances, when the typical characteristics of the reservoir itself change, the target layer should be divided according to the cycle characteristics of the electrical combination and the structural trend of the sand layer.

(2) In the small layers of the same lithology, the single yarn layer can be divided according to the muddy interlayer and the material interlayer.

(3) Moderate thickness. The divided single yarn layers generally have approximately the same thickness, usually in the range of $2 \mathrm{~m}-10 \mathrm{~m}$.

\subsubsection{Single Sand Layer Division and Comparison Mode}

The division and correlation mode of single sand layer is mainly based on logging curve characteristics combined with the cycle characteristics obtained by the above-mentioned maximum entropy spectrum analysis and wavelet analysis, using the same thickness of the sand body, channel 
down-cutting, lateral phase change, and overlapping sand all wells in the study area (Figure 7). bodies splitting and other modes to complete the division of

Liu111-24

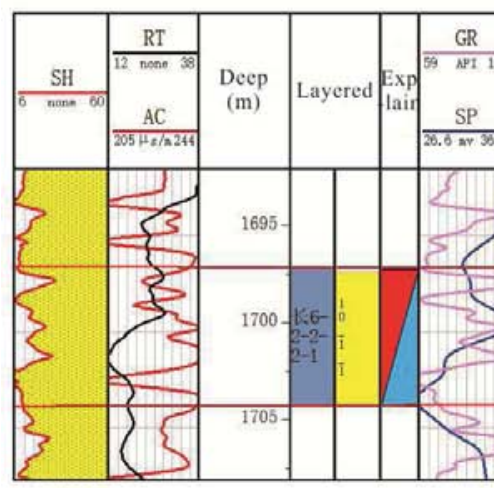

Liu111-25

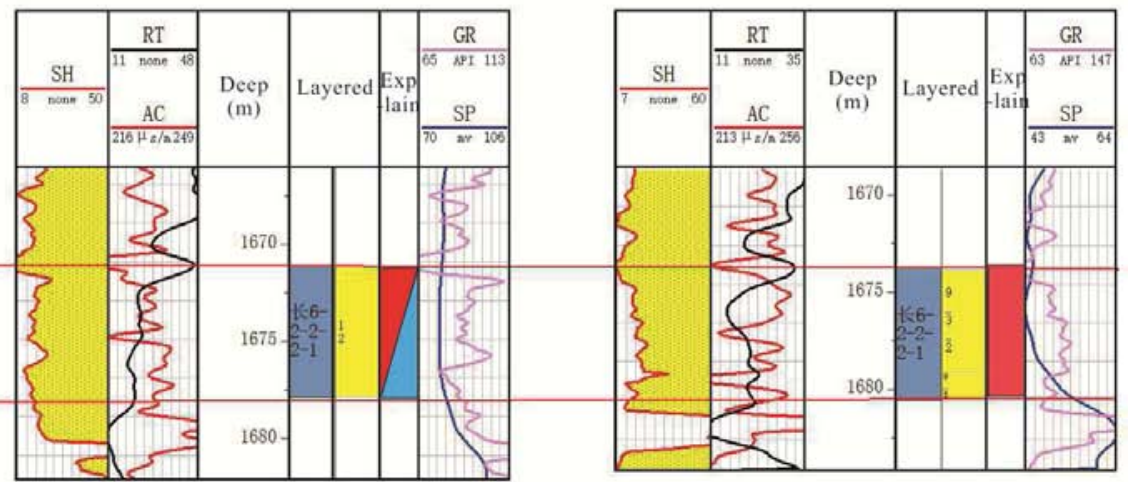

(a). Equal thickness correlation model of sand body
Liu111-26
Liu114-18

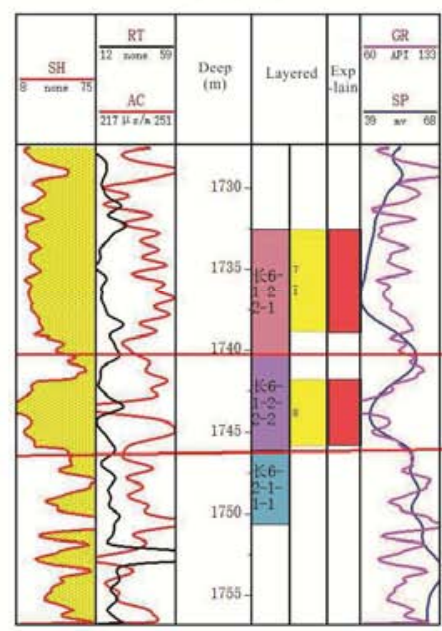

Liu114-19

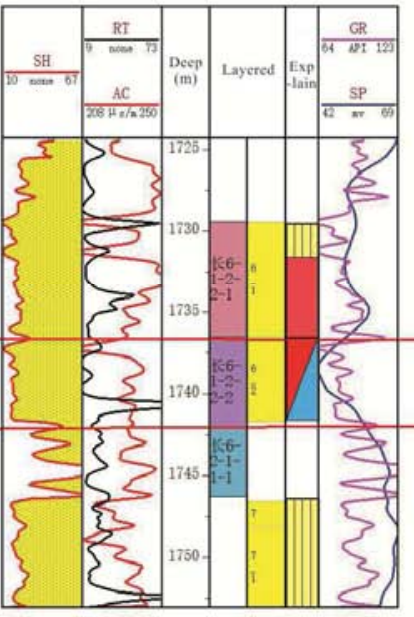

Liu114-20

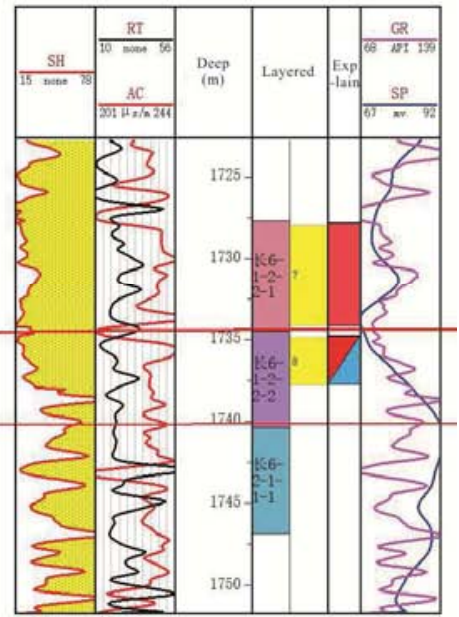

(b). Contrast model of channel down-cut of sand body

Liu124-22

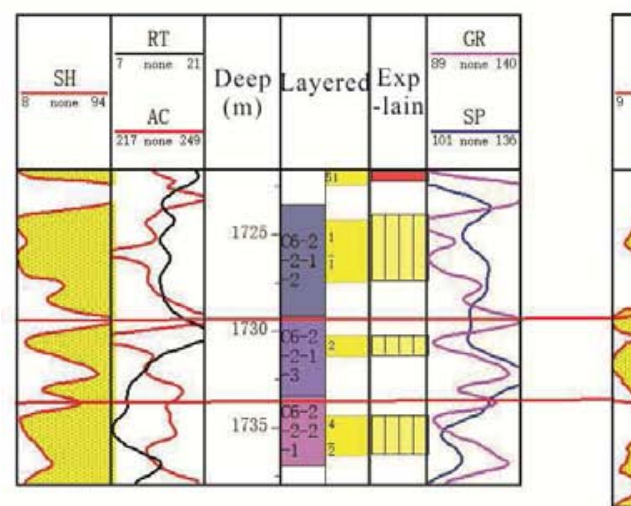

Liu123-23

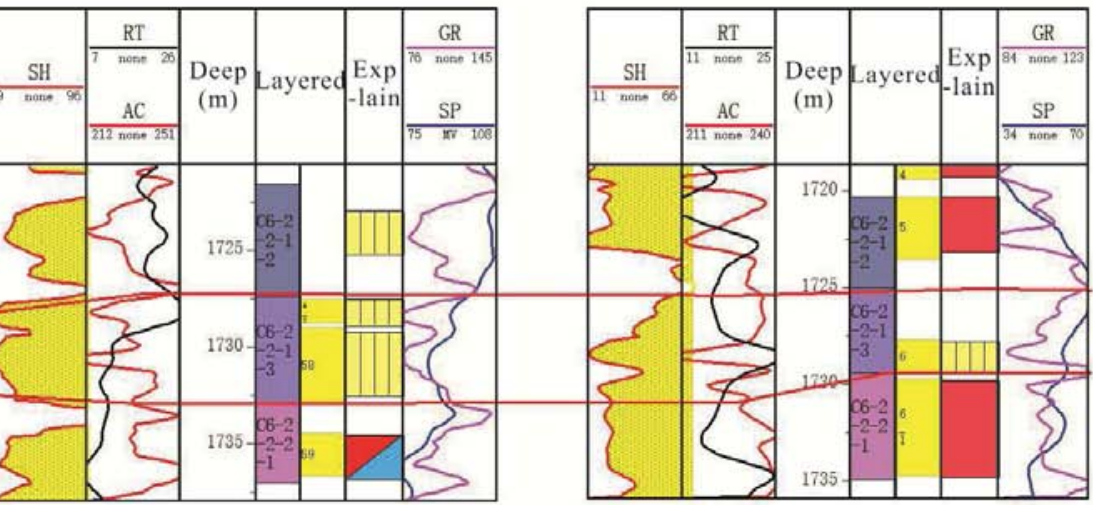

(c). Contrast model of lateral phase transformation of sand body 


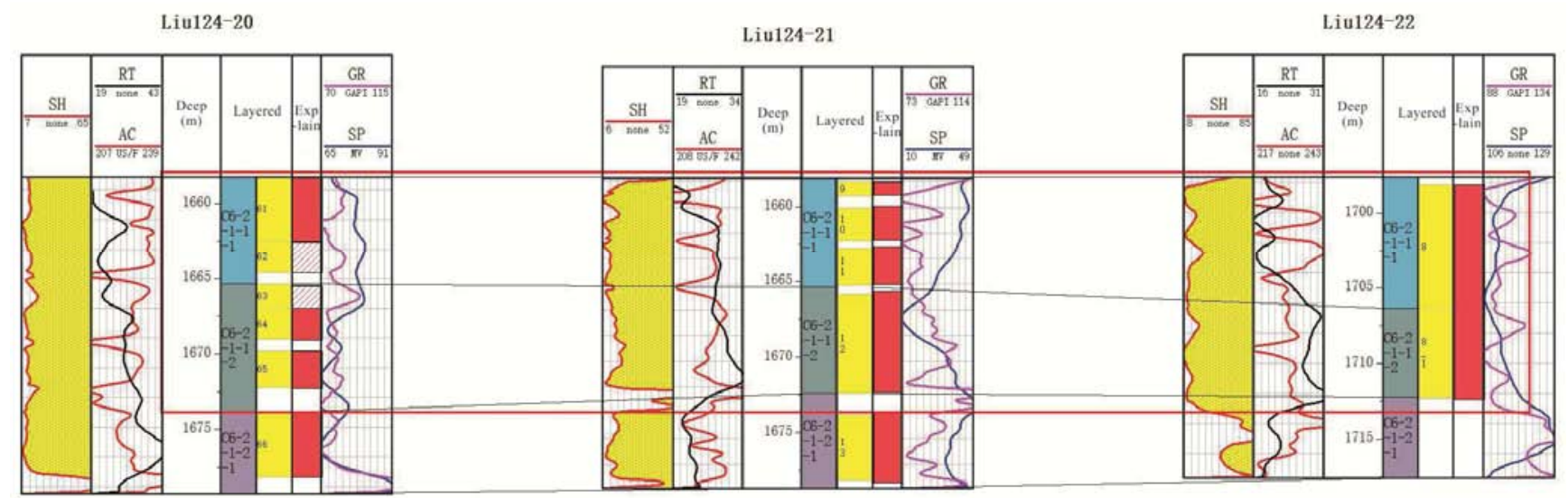

(d). Split superimposed sand model

Figure 7. Stratum sand body division pattern map.

\section{Stratigraphic Framework}

When performing stratigraphic profile comparison, there are usually two types of linked-well comparison profiles, one is parallel sedimentation trend and the other is vertical sedimentation trend. In this way, the morphological characteristics corresponding to each direction of the sand body can be understood more clearly [20]. By studying the results of multi-level sequence division and analyzing the sedimentary facies of single well in the study area, the isochronous stratigraphic correlation unit can be positioned on the ultra-short-term base cycle. Combining with the specific conditions of the same work area, the section with relatively complete stratigraphic sequence development and obvious marker bed is taken as the base section, and the comparison of the whole area is carried out in a vertical and parallel direction, as shown in Figure 8.

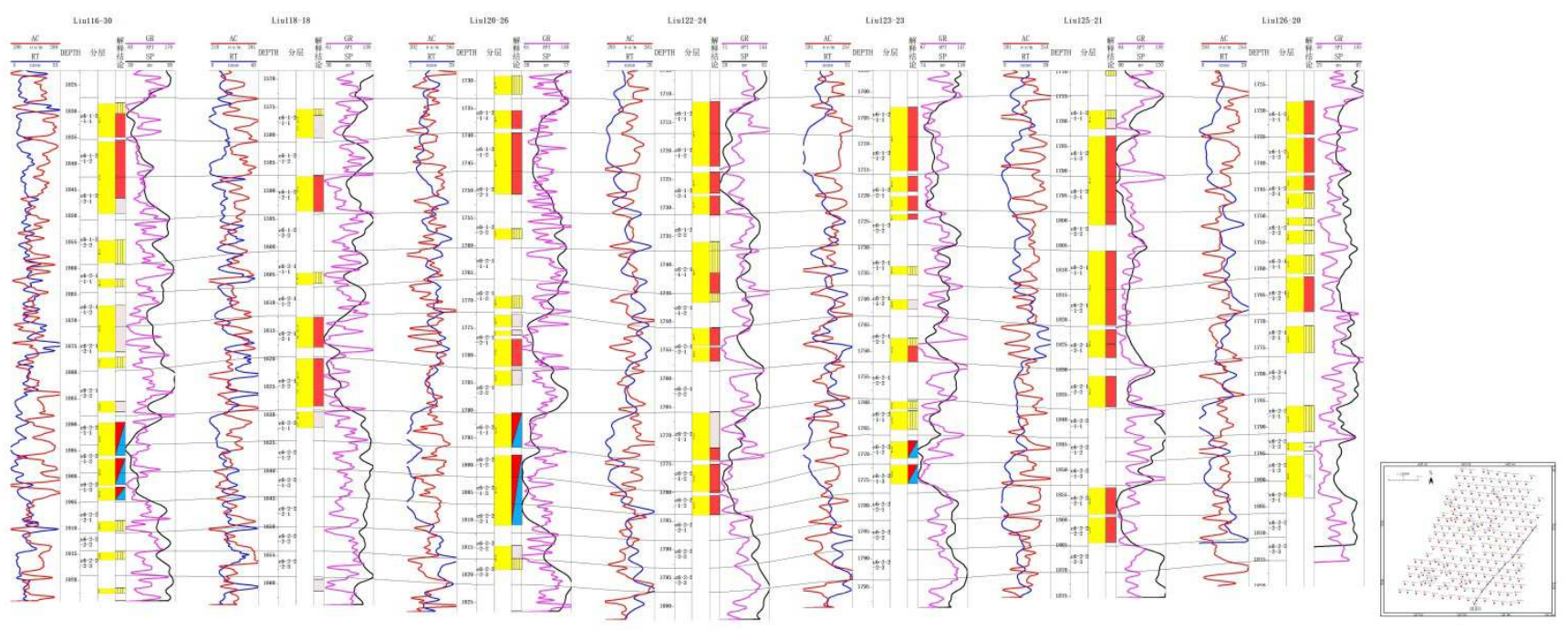

Figure 8. Linking wells in the study area compared to the backbone profile.

\section{Conclusion}

(1) Based on the methods and theories of sedimentology and high-resolution sequence stratigraphy, using wavelet cycle analysis and maximum entropy spectrum analysis techniques, and through sand body equal thickness, channel undercutting, lateral facies transformation and superimposed sand body splitting In the sub-layer division mode, the wells in the study area were finely divided into single sand bodies, and good results were obtained.

(2) The Chang 6 reservoir group in the study area is divided into 3 fourth-order cycles (sand formation), 6 fifth-order cycles (small layers), 13 sixth-order cycles (single-layer) and 21 seventh-order cycles (single sand body).

\section{References}

[1] Dai T. T., He W. X., Che Q., Delta Front Reservoir configuration and its influence on remaining oil distribution: A case study of Baibao oilfield, Ordos Basin. Petroleum Geology and engineering, 2017, (6): 69-73 (In Chinese).

[2] Li B., Peng. J., Xia Q. S., Xie J. T., Han M. J. Z., Diagenesis and reservoir quality of the Upper Triassic Chang 6 member in Jingan Oilfield, Ordos Basin, China [J]. Petroleum, 2018, 4 (2). 
[3] Wang J. B., He M. R., Yang Q., Study on Sedimentary microfacies of Chang 6 reservoir in Hu Lang Mao area, Jing'an County oilfield [J]. Neijiang Technology, (7): 139-140 (In Chinese).

[4] Xie R. J., Wang Y. X., Yang Z. P., A geological model under genetic stratigraphic framework: A case study of the 6-1 (1) subbeds in Hu Lang Mao area of Changqing Oilfield [J]. Journal of Petroleum and Natural Gas, (1): 16-23.

[5] Huang L., Reservoir engineering analysis in Hu Lang Mao area, Ordos Basin $[\mathrm{J}]$. China Petroleum \& Petrochemical, 2017, (03): 21-22 (In Chinese).

[6] Sun. Y. W., Li W., Liu Q., Y., Zhang M. D., Li. P., Zhang R., Shi X., In search of the inland Carnian Pluvial Event: MiddleUpper Triassic transition profile and $\mathrm{U}-\mathrm{Pb}$ isotopic dating in the Yanchang Formation in Ordos Basin, China [J]. Geological Journal, 2020, 55 (7).

[7] Yu Y., Lin L. B., Lan B. H., Hong W., Guo Y., Sequence stratigraphic division and recognition based on Wavelet Analysis: a case study of the Upper Permian Longtan formation in eastern Sichuan Basin [J]. Northwestern Geology, 2018, 51 (04): 43-52 (In Chinese).

[8] Xie G. G., Zheng J., Cycle Division based on Matlab wavelet analysis and its geological significance: A case study of Pinghu formation of PB-1 well in Pingbei section of Baojiao slope belt in Xihu Sag, east China Sea Basin [J]. Petroleum Geology of Xinjiang, 2016, 37 (02): 169-172 (In Chinese).

[9] Wu S. Y., Liu J., High resolution sequence stratigraphy based on time-frequency analysis. Marine geology and Quaternary Geology, 2015, 35 (04): 197-207.

[10] Ren J. F., Liao Y. T., Sun M., Zhao S., Liu X. L., Song. G. Z., High precision sequence stratigraphic quantitative division based on wavelet transform and its application [J]. Geophysics, 2013, 28 (05): 2651-2658 (In Chinese).

[11] Xu W., Liu P. C., Yu Z. H., Li C. L., High-resolution sequence stratigraphic cycle division and Correlation method in Block No. 30 of Sulige Gas Field [J]. Journal of xi 'an petroleum university (natural science edition), 2020, 35 (01): 28-33+41.
[12] Ou Y. Y., Xie J., Wang J. K., Wang D., Dong Y. X., Application of maximum entropy spectrum Analysis technology in the division and Comparison of small layers in South J block of Daan Oilfield [J]. Petroleum geology and engineering, 2017, 31 (02): 28-32+37+132 (In Chinese).

[13] Yuan R., Zhu R., Xie S. W., Hu W., Zhou F. J., Yu Y., Utilizing Maximum Entropy Spectral Analysis (MESA) to identify Milankovitch cycles in Lower Member of Miocene Zhujiang Formation in north slope of Baiyun Sag, Pearl River Mouth Basin, South China Sea [J]. Open Geosciences, 2019, 11 (1).

[14] Wang G. W., Deng Q. P., Tang W. Q., Log Spectral Analysis and its application in the study of sedimentary cycles [J]. Petroleum Exploration and development, 2002,(01): 93-95 (In Chinese).

[15] Zhang Y. P., Application of fine characterization of composite subsea distributary channel sand body in the development of $81 \sim 1$ reservoir in Ji Huang block 32 [J]. China mining, 2020, 29 (S1): 436-440+444 (In Chinese).

[16] Brian P. J. Williams, Robert D. Hillier. Variable alluvial sandstone architecture within the Lower Old Red Sandstone, southwest Wales [J]. Geological Journal, 2004, 39 (3-4).

[17] Guo Y., Single sand body characterization of Baijiantan District formation reservoir in the Dzungar basin 7 Middle East region [J]. China Manganese, 2019, 37 (02): 57-60 (In Chinese).

[18] Zhou X. M., Hu Y. L., Gao X. J., Zhang Z., Chen J. Y., Wang J. Q., Application of fine description of meandering river single sand body in secondary development of old oilfield [J]. Petroleum Geology of Xinjiang, 2010, 31 (03): 284-287 (In Chinese).

[19] F Prakojo, G Lobova, R Abramova. Predicted facies, sedimentary structures and potential resources of Jurassic petroleum complex in S-E sWestern Siberia (based on well logging data). 2015, 27 (1).

[20] Feng C. J., Zhao Y., Jia P., Discussion on reservoir configuration model of Shallow Lake Basin Delta [J]. Geoscience, 2013, 48 (4): 1234-1245 (In Chinese). 